\title{
Relating field-aligned beams to inverted-V structures and visible auroras
}

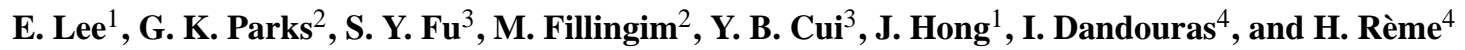 \\ ${ }^{1}$ School of Space Research, Kyung Hee University, Yongin, Gyeonggi, South Korea \\ ${ }^{2}$ Space Sciences Laboratory, University of California, Berkeley, CA, USA \\ ${ }^{3}$ School of Earth and Space Sciences, Peking University, Beijing, China \\ ${ }^{4}$ CNRS, IRAP, 9 Ave. Colonel Roche, Toulouse, France \\ Correspondence to: G. K. Parks (parks@ssl.berkeley.edu)
}

Received: 31 May 2015 - Revised: 14 August 2015 - Accepted: 24 September 2015 - Published: 15 October 2015

\begin{abstract}
The ion composition experiment on Cluster measures 3-D distributions in one spin of the spacecraft $(4 \mathrm{~s})$. These distributions often measure field-aligned ion beams $\left(\mathrm{H}^{+}, \mathrm{He}^{+}\right.$and $\left.\mathrm{O}^{+}\right)$accelerated out of the ionosphere. The standard model of these beams relies on a quasi-static Ushaped potential model. The beams contain important information about the structure and distribution of the U-shaped potential structures. For example, a simple beam with a narrow velocity range tells us that the particles are accelerated going through a quasi-static U-shaped potential structure localized in space. A more complex beam with a large range of velocities varying smoothly (a few tens of kilometers per second to $>100 \mathrm{~km} \mathrm{~s}^{-1}$ ) tells us that the potential structure is extended and distributed along the magnetic field. The Cluster experiment has now revealed new features about the beams. Some beams are broken into many individual structures each with their own velocity. The U-shaped potential model would interpret the new features in terms of particles accelerated by narrow isolated potential structures maintained over an extended region of the magnetic field. Another interpretation is that these features arise as Cluster traverses toward the center of a small-scale U-shaped potential region detecting particles accelerated on different equipotential contours. The estimate of the distance of the adjacent contours is $\sim 590-610 \mathrm{~m}$ at a Cluster height of $\sim 3.5 R_{\mathrm{E}}$. The observed dimensions map to $\sim 295-305 \mathrm{~m}$ in the ionosphere, suggesting Cluster has measured the potential structure of an auroral arc.
\end{abstract}

Keywords. Ionosphere (auroral ionosphere; particle acceleration) - magnetospheric physics (auroral phenomena)

\section{Introduction}

The electric field parallel to magnetic field direction $\left(\boldsymbol{E}_{\|}\right)$ is fundamentally important for accelerating laboratory, space and astrophysical plasmas. The best-documented observations of $\boldsymbol{E}_{\|}$come from Earth's aurora. The first evidence of $\boldsymbol{E}_{\|}$was obtained by satellite observations of auroral electron and ion beams that were accelerated in opposite directions along the magnetic field (Shelley et al., 1972). Satellites traversing the auroral acceleration region have since shown that the auroral beams of different energies form an inverted-V shape when the particle flux is plotted against time (Heikkila, 1970; Frank and Ackerson, 1971; Carlson et al., 1998; Marklund et al., 2011; Cui et al., 2014). The standard interpretation of how the inverted- $\mathrm{V}$ feature arises is that particles are accelerated in a quasi-steady U-shaped auroral potential structure (Carlqvist and Boström, 1970). In $\mathrm{U}$-shaped potential structures, the equipotential surfaces are assumed to be symmetric and parallel to the magnetic field direction and the potential drop $\Delta \Phi$ at any altitude is at a maximum at the center and decreases monotonically toward the sides. A detector moving across such a potential structure will thus detect electrons and ions with increasing energy toward the center before the maximum and with decreasing energy after the maximum, producing an inverted- $\mathrm{V}$ feature in energy-time spectrogram plots. In a negative potential structure, ions are accelerated upward and electrons downward (to produce the auroral emissions) and the electric field converges at the bottom of the flow shear zone; the equipotential contours form a characteristic U-shaped contour (Carlson et al., 1998; Marklund et al., 2011; Cui et al., 2014). 
There is a puzzle of why the dimensions of inverted$\mathrm{V}$ structures measured by satellites and rockets are different from typical auroral dimensions. Satellite measurements have shown that the inverted- $\mathrm{V}$ structures have dimensions of a few hundred kilometers in latitude, and rocket measurements have shown that they are several kilometers (Heikkila, 1970; Frank and Ackerson, 1971; Arnoldy, 1974; Bosqued et al., 1985; Carlson et al., 1998). Recently, 5 years of the Fast Auroral SnapshoT Explorer (FAST) data have shown that the usual width of an inverted-V varies from 20 to $40 \mathrm{~km}$, which is comparable to the peak value of the typical mesoscale auroral arc width of 10-20 km (Partamies et al., 2008). From Freja and Cluster observations, the scale sizes of auroral electric field structures were reported to be $\sim 1-$ $5 \mathrm{~km}$ (Karlsson and Marklund, 1996; Johansson et al., 2007). However, these dimensions are much larger than the dimensions of a typical aurora. Various forms of auroras optically determined from a ground-based orthicon television camera (Davis, 1966) showed that the auroral dimensions can be as small as $\sim 70 \mathrm{~m}$, and most of the auroral structures have dimensions less than $\sim 1 \mathrm{~km}$ (Maggs and Davis, 1968). Observations by Maggs and Davis (1968) have also established that the dimensions of the aurora when not measured along the magnetic zenith direction are much larger than the actual dimensions.

Information about the U-shaped potential structure is contained in the different types of field-aligned beams. Fieldaligned auroral ion beams $\left(\mathrm{H}^{+}, \mathrm{He}^{+}\right.$and $\left.\mathrm{O}^{+}\right)$are frequently measured accelerated out of the auroral ionosphere. The escaping beams can be narrow in velocity space or more extended with a continuous range of velocities. Narrow velocity beams indicate that the particles have been accelerated by a potential localized in space, and beams with a wider continuous velocity range indicate that ions have been accelerated over an extended potential structure distributed along the magnetic field.

In this study, we present a new feature of the upward flowing ionospheric ion beams in the auroral region observed by the Cluster ion spectrometry (CIS) experiment (Escoubet et al., 2001; Rème et al., 2001). The new feature is that the upward flowing $\mathrm{H}^{+}, \mathrm{He}^{+}$and $\mathrm{O}^{+}$beams can include multiple discrete structures, each with a narrow velocity range but extending over a wide velocity range. These multiple discrete beams are not easily interpreted using the standard auroral potential model because they would require the existence of as many narrow isolated potential structures as the number of beams along the magnetic field. There are no models or theories that can explain how the multiple discrete potential structures can be formed and maintained. We suggest that the multiple discrete beams are accelerated on the different equipotential contours, which have small spatial scales, when Cluster crossed an auroral potential structure at a height of $3.5 R_{\mathrm{E}}$. This new measurement will resolve why the dimension of inverted- $\mathrm{V}$ structures obtained by satellites and rockets is different from the dimensions of typical auroras.

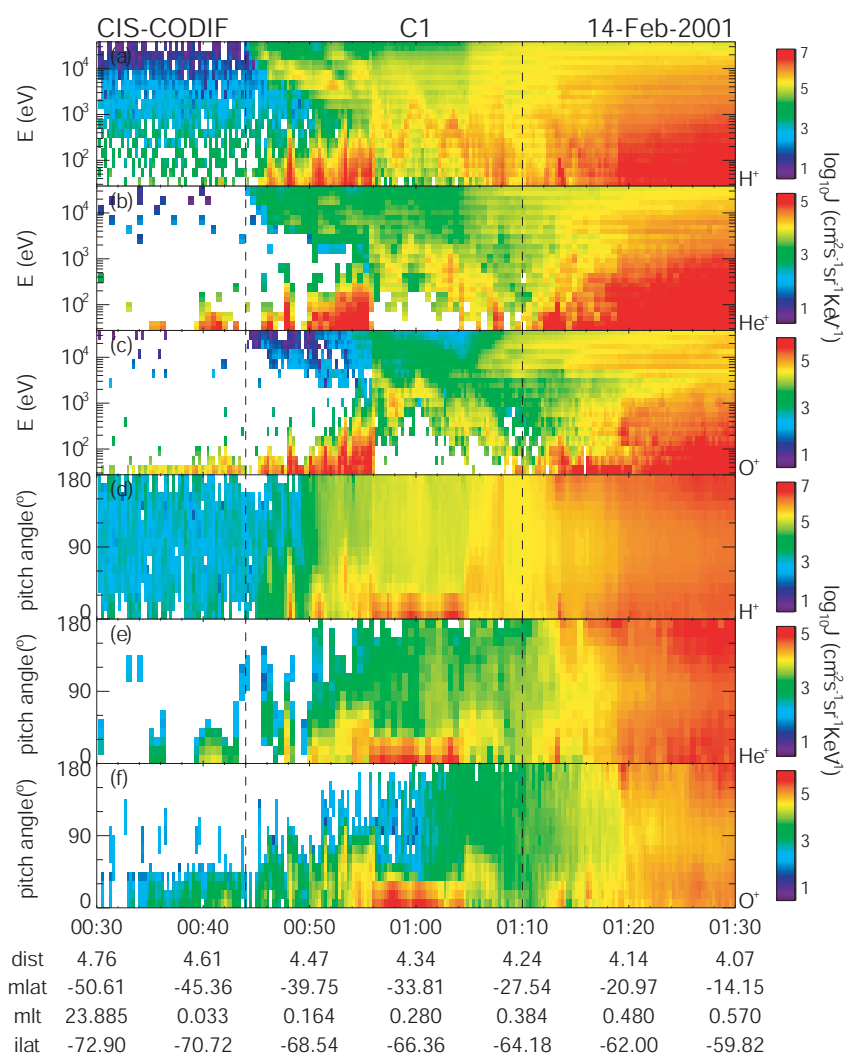

Figure 1. A summary plot of the ion measurements on Cluster 1. Panels (a)-(c) show the differential number flux spectrogram of $\mathrm{H}^{+}, \mathrm{He}^{+}$, and $\mathrm{O}^{+}$, while panels (d)-(f) show the pitch-angle distributions of these ions. The inverted- $\mathrm{V}$ features appeared sporadically in all ion species. The position of the spacecraft is shown at the bottom. The spacecraft was traversing the Southern Hemisphere just after local midnight.

\section{Observations}

Ion beams leaving the ionosphere are frequently observed by Cluster. We have examined about 30 different days when inverted-V structures were observed. In this article we show examples from 14 February 2001 to illustrate the new features. Figure 1 shows a summary plot from 14 February 2001, during which field-aligned ion beams associated with inverted V-feature were observed streaming out of the ionosphere. The inverted-V structure was observed just after magnetic local midnight. The four Cluster satellites were passing through the perigee at geocentric distance of $\sim 4.8 R_{\mathrm{E}}$. The ion data were obtained by the composition and distribution function (CODIF) experiment on Cluster 1 (C1), 3 (C3), and 4 (C4) (Rème et al., 2001), which measures ion species $-\mathrm{H}^{+}$, $\mathrm{He}^{+}$, and $\mathrm{O}^{+}-$from Earth's ionosphere and distinguishes them from the $\mathrm{He}^{++}$ions of the solar wind. These beams are measured within the spin-time resolution of $4 \mathrm{~s} 3$-D distributions. This experiment includes a time of flight (TOF) detector and obtains 3-D distributions of the different ion species 


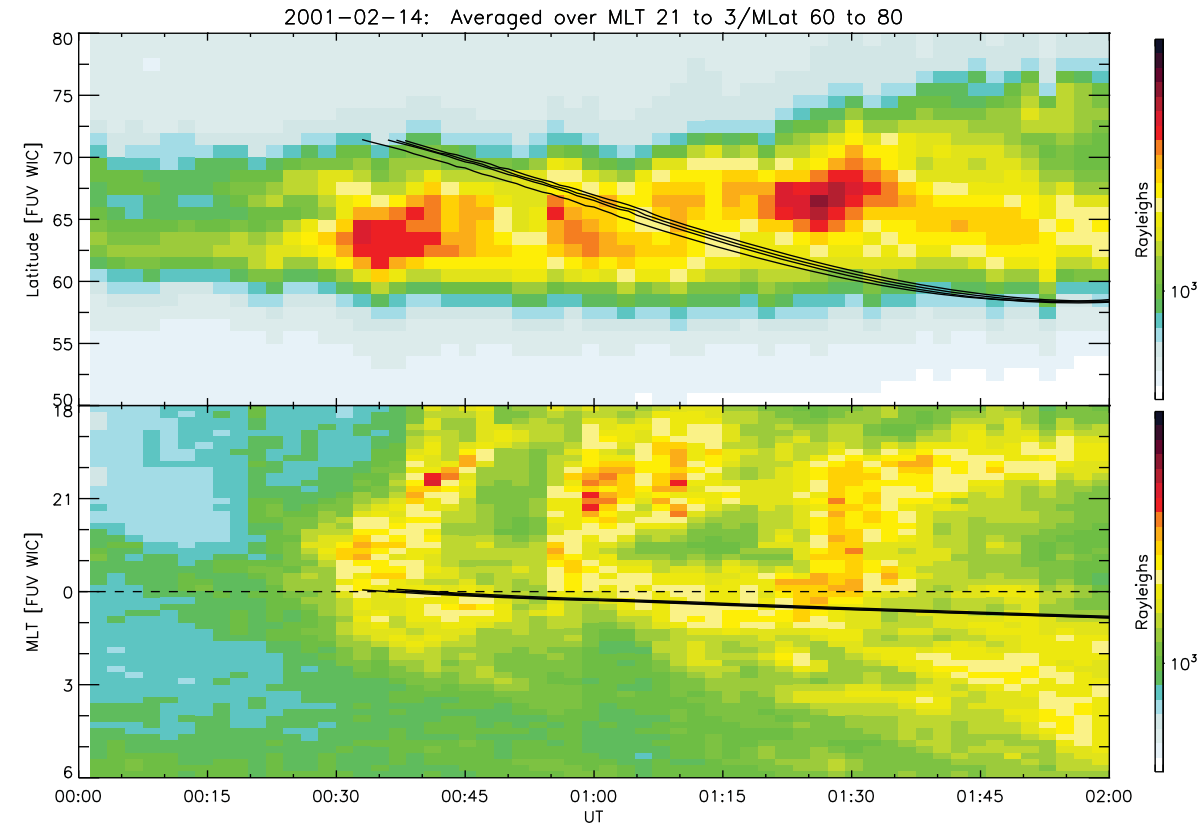

Figure 2. Keogram of global auroral images during the observations of ion beams flowing out of the ionosphere. The top panel shows the aurora in geomagnetic latitude as a function of universal time and the bottom panel shows magnetic local time vs. universal time. The right color bar shows the intensity of the aurora in rayleighs. The black lines are footprints of the satellite using several different models (caveat: Cluster was in the Southern Hemisphere, while the auroral picture comes from the Northern Hemisphere).

from $\sim 21 \mathrm{eV}$ to $38 \mathrm{keV}$ ions. The experiment has eight detectors aligned along the polar direction separated by $22.5^{\circ}$, and the high voltage (HV) sweeps over the energy range from $\sim 21 \mathrm{eV}$ to $38 \mathrm{keV} 32$ times as the spacecraft spins, producing 2-D distributions with a time resolution of $0.125 \mathrm{~s}$.

The top three panels of Fig. 1 show differential number flux spectrograms of $\mathrm{H}^{+}, \mathrm{He}^{+}$and $\mathrm{O}^{+}$from $\mathrm{C} 1$. On the basis of different plasma properties, the interval has been divided into three separate regions: lobe (00:30-00:44 UT), plasma sheet boundary layer (PSBL) (00:44-01:10 UT) and plasma sheet (after 01:10 UT). The pitch-angle spectrograms of the ions in the PSBL (bottom three panels) show that the ions are field-aligned, and all measurements come from the pitch-angle bins closest to the magnetic field direction. Important features on this day include time-dispersed ion injections observed in all ion species beginning around 00:44 UT, previously studied by Keiling et al. (2004), who showed that the injection included four to five "beamlets" separated by $\sim 100 \mathrm{~s}$. Injections of the lower-energy ions of $\sim 1 \mathrm{keV}$ occurred in coincidence with these beamlets. As the spacecraft entered into the inner boundary of the PSBL (after 00:55 UT), higher-energy ions and inverted-V structures were observed; see Cui et al. (2014) for further discussion of these inverted- $\mathrm{V}$ events.

The keograms covering the same period, constructed from the individual Wideband Imaging Camera (WIC) far ultraviolet (FUV) auroral images (Mende et al., 2000), are shown in Fig. 2. In each keogram, the top panel shows the auro- ral intensity as a function of magnetic latitude (MLat), and the second panel shows it as a function of magnetic local time (MLT). The solid black lines are footprints of $\mathrm{C} 1$ in the Southern Hemisphere, using different models including the Tsyganenko 89 (T89) and Tsyganenko 96 (T96) (Tsyganenko and Stern, 1996) models (the two models essentially gave the same results). The keograms come from auroras in the Northern Hemisphere, and the magnetic field of the Southern Hemisphere was mapped to the Northern Hemisphere using the procedure from the Satellite Situation Center (http://sscweb.gsfc.nasa.gov/). It uses the International Geomagnetic Reference Field (IGRF) with the Tsyganenko 89c model with $\mathrm{Kp}=3$. It starts with the spacecraft position and follows the modeled field line in both directions. It stops when the field line reaches an altitude of $100 \mathrm{~km}$ (that is, the foot point) or an altitude of $70 R_{\mathrm{E}}$ (considered open). This way, it gives both the northern and southern footpoints simultaneously (assuming that they both exist).

We now focus on the low-energy ion beams beginning around 00:45 UT. The keogram shows that the spacecraft passed through close to magnetic local midnight. Figure 3 shows examples of $\mathrm{H}^{+}, \mathrm{He}^{+}$and $\mathrm{O}^{+}$ions plotted in the velocity space. These plots are 2-D cuts of 3-D distributions obtained with a time resolution of $4 \mathrm{~s}$ (every spin). The phase space densities are plotted in the plane defined by the velocity parallel $\left(V_{\|}\right)$and perpendicular $\left(V_{\perp}\right)$ to the direction of the magnetic field in the spacecraft frame of reference. The first row shows $\mathrm{H}^{+}$ions for three times, the second row $\mathrm{He}^{+}$ 

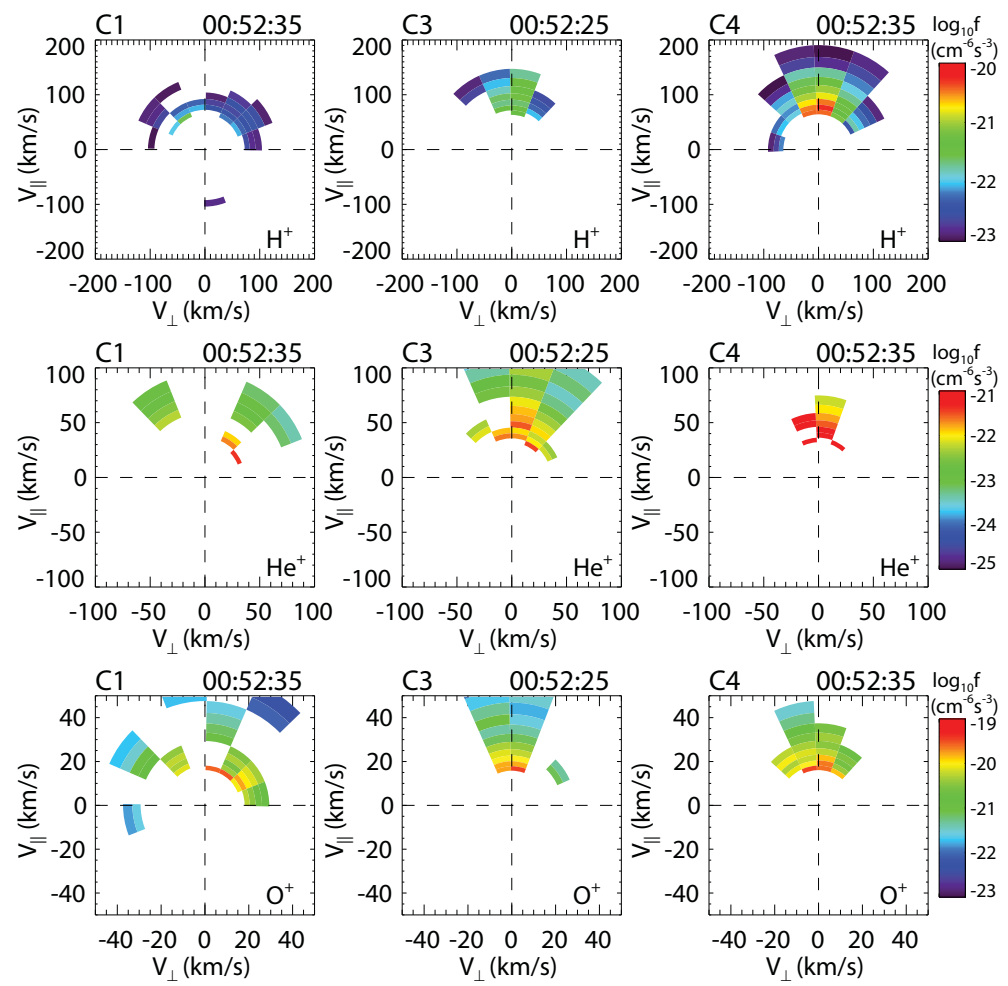

Figure 3. Four types of field-aligned velocity distributions observed by Cluster. These are the 2-D cuts of the 3-D distributions obtained with spin-time resolutions of $4 \mathrm{~s}$. The top row shows $\mathrm{H}^{+}$distribution, the middle row $\mathrm{He}^{+}$, and the bottom row $\mathrm{O}^{+}$. The three columns are observations from Cluster 1,3, and 4. Four types of beams (beams with narrow velocity range; a more complex distribution with larger velocity range; multiple discrete beams each with different velocity; and beams off the magnetic field axis, possibly ion conics) are observed for all ion species and all Cluster spacecraft. Note that the velocity scales of the plots are different.

ions and the bottom row $\mathrm{O}^{+}$ions. The three columns show data from $\mathrm{C} 1,3$ and 4 . The four Cluster spacecraft were in the Southern Hemisphere, and thus positive $V_{\|}$corresponds to ions moving upward along the magnetic field direction leaving the southern auroral ionosphere. (Note that the sampling times onboard the different spacecraft when the distributions were obtained are slightly different).

These plots show three types of field-aligned beams (FABs). The first is an isolated beam with a narrow velocity range (for example, $\mathrm{H}^{+}$with $V_{\|} \sim 75 \mathrm{~km} \mathrm{~s}^{-1}$, at 00:52:35 UT; top left on C1). The second is a FAB with a wider range of $V_{\|}$values $\left(V_{\|}\right.$from $\sim 50-110 \mathrm{~km} \mathrm{~s}^{-1}$ at 00:52:41 UT; top middle panel, C3) and the third multiple discrete beams each with its own $V_{\|}\left(V_{\|}\right.$at $\sim 25$ and $50 \mathrm{~km} \mathrm{~s}^{-1}$ for $\mathrm{He}^{+}$at 00:52:35 UT; middle right panel, C4). These multiple beams have been observed for all ion species $-\mathrm{H}^{+}, \mathrm{He}^{+}$and $\mathrm{O}^{+}$. Multiple discrete beams are also seen sometimes in beams at larger pitch angles, some of which may be identified as ion conics (Temerin et al., 1982). A survey of several hundred FAB events of upward flowing ions indicates that the multiple discrete beams occur regularly throughout the upward flowing beams. They are seen on all spacecraft, and the multiple beams appear randomly.
No specific local plasma conditions could be associated with their presence.

To interpret the features of the beams, note that the energy per charge of an ion that has gone through a potential drop $\Delta \phi$ measured by CODIF is $m v^{2} / 2 q=\left(W_{\text {th }} / q\right)+\Delta \phi$, where $W_{\text {th }}$ is the thermal energy. The thermal energy of the ambient ionospheric plasma is $<1 \mathrm{eV}$; hence, we assume it is much less than the potential drop $\left(W_{\text {th }} \ll q \Delta \phi\right)$. If so, the peak of the ion beam distribution in velocity space will correspond to the energy gained going through the potential drop. A simple $\mathrm{H}^{+}$beam with a velocity of $75 \mathrm{~km} \mathrm{~s}^{-1}$ (top left) indicates that the ions have undergone a potential drop of $\sim 30 \mathrm{~V}$ along the magnetic field (after correcting for the spacecraft potential). For beams with a larger velocity range, which smoothly varies (top right), it is argued that the potential is extended along $\mathbf{B}$ and the higher-velocity ions correspond to ions starting at lower altitudes that have gone through a larger potential drop, gaining more energy. For example, for velocities varying from 60 to $150 \mathrm{~km} \mathrm{~s}^{-1}$, the potential drops correspond to $\sim 20-120 \mathrm{~V}$. Note that later in the PSBL, following the breakup of the aurora at $\sim 00: 55$ UT (not shown), the peak inverted-V structures reached $\sim 6 \mathrm{keV}$.

Field-aligned beams with as many as five discrete beams have been observed, with each having a different velocity. An 
estimate of the distance traveled between consecutive FABs can be obtained by using information from 2-D distributions, sampled every $125 \mathrm{~ms}$. Multiplying the spacecraft velocity of $\sim 4.7-4.9 \mathrm{~km} \mathrm{~s}^{-1}$ with the sampling time of $0.125 \mathrm{~s}$ shows that the spacecraft has traveled $\sim 590-610 \mathrm{~m}$. This distance mapped to the ionosphere using the T96 model indicates that the footprint of Cluster has moved $\sim 295-305 \mathrm{~m}$. This distance is very typical of the auroral arc dimensions measured by Maggs and Davis (1968). Thus, our suggestion is that the discrete beams measured by Cluster represent the separation distance between the equipotential contours in auroral arcs.

We can also examine whether the different ion species have gone through the same or a different amount of potential drops. The plots in the right column show that the lowest measured velocity of the $\mathrm{H}^{+}$beam at 00:52:35 UT is $\sim 75 \mathrm{~km} \mathrm{~s}^{-1}$, that of the $\mathrm{He}^{+}$beam is $\sim 35 \mathrm{~km} \mathrm{~s}^{-1}$ and that of the $\mathrm{O}^{+}$beam is $\sim 18 \mathrm{~km} \mathrm{~s}^{-1}$. These beams come from the same $\mathrm{C} 4$, and the measured ratio of beam velocities of $\mathrm{O}^{+}$ to $\mathrm{H}^{+}$is $\sim 0.24$ and that of $\mathrm{He}^{+}$to $\mathrm{H}^{+}$is $\sim 0.47$. These values are within the uncertainties of the theoretical ratios of the beam velocities of $\mathrm{O}^{+}$and $\mathrm{He}^{+}$to $\mathrm{H}^{+}$if all of the ions have gone through the same potential drop: $V_{\mathrm{H}+}=2 V_{\mathrm{He}+}$ and $V_{\mathrm{H}+}=4 V_{\mathrm{O}+}$. Thus, our observations indicate that these ions originated from nearly the same height and each ion has gone through $\sim 30-40$ Volts of potential drop. For a Maxwellian distribution, the temperature of the beams can be estimated from the width of the distribution. The estimated temperatures of $\mathrm{H}^{+}, \mathrm{He}^{+}$and $\mathrm{O}^{+}$ions (in units of $k \mathrm{~T}$ where $k$ is the Boltzmann constant) are $\sim 50,75$ and $100 \mathrm{eV}$, respectively, indicating that the temperature of $\mathrm{O}^{+}$is larger than that of $\mathrm{H}^{+}$or $\mathrm{He}^{+}$. Mass-dependent heating has been previously observed not only in Earth's auroras but also on the Sun (Reiff et al., 1988; Collin et al., 1987; Möbius et al., 1998; Cui et al., 2014; Cranmer et al., 1999; Marsch et al., 2004).

\section{Discussion}

In this paper, we have presented a new feature in outflowing auroral ion beams, which can be used to obtain information about the U-shaped potential structure. The new feature is that auroral ion beams consist of multiple discrete beams, each with a different velocity. This has not been discussed previously although a careful examination of figures previously published of beams indicates the presence of multiple beam structures (see Fig. 3 of McFadden et al., 1998, Fig. 1 of Lund et al., 1998 and Fig. 1 of Möbius et al., 1998). The new feature has been interpreted in terms of a small-scale potential structure and indicates that Cluster was measuring particles accelerated by different potential contours. Figure 4 shows an illustration of the potential structure in the acceleration region. The large-scale U-shaped potential structure exists, encompassing the whole inverted-V structure and multiple small-scale potential structures, each of which, producing beams with different energies, are embedded within the

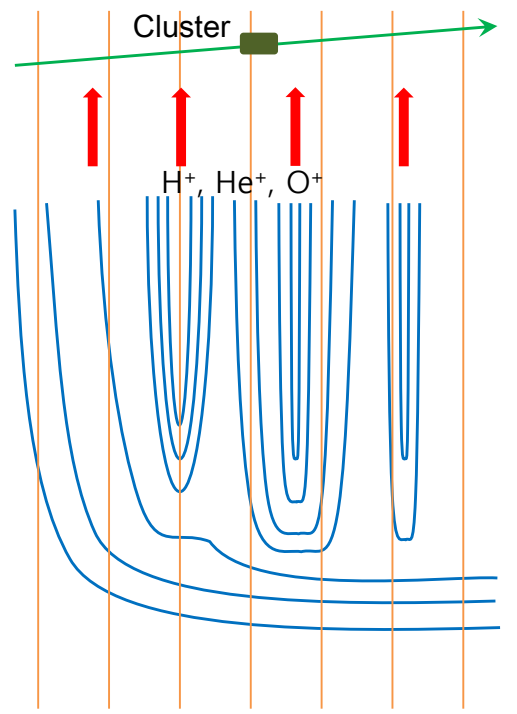

Figure 4. An illustration of the potential structure showing equipotential contours (blue lines) in the auroral acceleration region. Magnetic field lines (orange lines) and outflowing ions (red arrows) are also shown. Cluster was passing through such a structure at a height of $\sim 3.5 R_{\mathrm{E}}$.

large-scale structure. Based on these beam features, the distances of the adjacent small-scale potential structures have been estimated. The small distances of a few hundred meters lend support to the idea that Cluster was measuring the potentials of auroral arcs. Our observations clarify the puzzle of why the dimensions of inverted-V structures measured by satellites and rockets are different from the dimensions of typical auroras.

A qualitative new picture that is now emerging from our study is that low-energy ionospheric ion beams are continually escaping from the polar regions of Earth during both quiet and disturbed geomagnetic times. These beams include the polar wind, upwelling ions from the cusps and polar caps, and ion beams accelerated in the aurora by electric field parallel to the magnetic field direction. These ions are a significant plasma source for the lobes and the plasma sheet regions in the geomagnetic tail (Parks et al. (2015) and references therein).

A recent investigation of the behavior of ion beams in inverted-V structures consisting of $\mathrm{H}^{+}, \mathrm{He}^{+}$, and $\mathrm{O}^{+}$showed that the ions are heated while accelerated along the magnetic field direction (Cui et al., 2014). The $\mathrm{He}^{+}$and $\mathrm{O}^{+}$ions are generally hotter than $\mathrm{H}^{+}$confirming the results from previous studies (Collin et al., 1981; Reiff et al., 1988; Möbius et al., 1998). However, the results of Cui et al. (2014) show that the ion beam density $\delta n_{\mathrm{b}}$ and temperature $T_{\|}$increase as the streaming velocity $V_{\mathrm{b}}$ increases in the inverted- $\mathrm{V}$ structure. The parallel temperature $T_{\| \mid}$starts out a few tens of $\mathrm{eV}$ in the beginning, where the beam density is small $\left(\delta n_{\mathrm{b}} / n_{T}<0.1\right)$, and increases to a few hundred $\mathrm{eV}$ at the peak, where the 
beam density reaches maximum $\left(\delta n_{\mathrm{b}} / n_{T}>0.3\right)$. These results interpreted in terms of a U-shaped potential structure indicate that the hottest ions come from the central region, where the potential difference is at a maximum. Preferential heating of heavier masses has also been observed in the solar corona (Kohl et al., 1998). Several suggested heating mechanisms include wave-particle resonance interactions and multistream instabilities (e.g., Hudson et al., 1983; Kaufmann et al., 1986; Dusenbery et al., 1988; Bergmann and Lotko, 1986; Malkki et al., 1989; Cranmer et al., 1999; Marsch, 2006). However, which of these mechanisms is active remains unknown and needs further study.

Acknowledgements. This research work is in part supported by a NASA grant to the University of California, Berkeley, NNX11AD49G-2/15. The work by E. Lee was in part supported by the BK21 Plus Program and Basic Science Research Program (NRF-2013R1A1A2010711) through the National Research Foundation funded by the Ministry of Education of Korea. The authors thank the Cluster instrument teams and the Cluster Science Archive for the use of the data.

Edited by: C.-P. Escoubet

\section{References}

Arnoldy, R. L.: Review of auroral particle precipitation, in: Physics of Auroral Arc Formation, Geophys. Monogr. Ser., 25, edited by: Akasofu, S.-I. and Kan, J. R., AGU, Washington, D.C., 56-66, doi:10.1029/GM025p0056, 1981.

Bergmann, R. and Lotko, W.: Transition to unstable ion flow in parallel electric fields, J. Geophys. Res., 91, 7033, doi:10.1029/JA091iA06p07033, 1986.

Bosqued, J. M., Maurel, C., Rème, H., Sauvaud, J. A., and Kovrazhkin, R. A.: Statistical study on inverted-V events: A comparison between experiment and theory, Adv. Space Res., 5, 135, doi:10.1016/0273-1177(85)90127-9, 1985.

Carlqvist, P. and Boström, R.: Space-charge regions above the aurora, J. Geophys. Res., 75, 7140, doi:10.1029/JA075i034p07140, 1970.

Carlson, C. W., McFadden, J. P., Ergun, R. E., Temerin, M., Peria, W., Mozer, F. S., Klumpar, D. M., Shelley, E. G., Peterson, W. K., Möbius, E., Elphic, R., Strangeway, R., Cattell, C., and Pfaff, R.: FAST observations in the downward auroral current region: Energetic upgoing electron beams, parallel potential drops, and ion heating, Geophys. Res. Lett., 25, 2017, doi:10.1029/98GL00851, 1998.

Collin, H. L., Sharp, R. D., Shelley, E. G., and Johnson, R. G.: Some general characteristics of upflowing ion beams over the auroral zone and their relationship to auroral electrons, J. Geophys. Res., 86, 6820, doi:10.1029/JA086iA08p06820, 1981.

Collin, H. L., Peterson, W. K., and Shelley, E. G.: Solar cycle variation of some mass dependent characteristics of upflowing beams of terrestrial ions, J. Geophys. Res., 92, 4757, doi:10.1029/JA092iA05p04757, 1987.

Cranmer, S. R., Field, G. B., and Kohl, J. L.: Spectroscopic constraints on models of ion cyclotron resonance heating in the polar solar corona and high-speed solar wind, Astrophys. J., 518, 937, doi:10.1086/307330, 1999.

Cui, Y., Fu, S. Y., and Parks, G. K.: Heating of ionospheric ion beams in inverted-V structures, Geophys. Res. Lett., 41, 37523758, doi:10.1002/2014GL060524, 2014.

Davis, T. N.: The application of image orthicon techniques to aurora1 observation, Space Sci. Rev., 6, 222, doi:10.1007/BF00222594, 1966.

Dusenberry, P. B., Martin, R. F., and Winglee, R. M.: Ion-ion waves in the auroral region: Wave excitation and ion heating, J. Geophys. Res., 93, 5655, doi:10.1029/JA093iA06p05655, 1988.

Escoubet, C. P., Fehringer, M., and Goldstein, M.: Introduction The Cluster mission, Ann. Geophys., 19, 1197-1200, doi:10.5194/angeo-19-1197-2001, 2001.

Frank, L. A. and Ackerson, K. L.: Observations of charged particle precipitation into the auroral zone, J. Geophys. Res., 76, 3612, doi:10.1029/JA076i016p03612, 1971.

Heikkila, W. J.: Satellite observations of soft particle fluxes in the auroral zone, Nature, 225, 369, doi:10.1038/225369a0, 1970.

Hudson, M. K., Lotko, W., Roth, I., and Witt, E.: Solitary waves and double layers on auroral field lines, J. Geophys. Res., 88, 916, doi:10.1029/JA088iA02p00916, 1983.

Johansson, T., Marklund, G., Karlsson, T., Liléo, S., Lindqvist, P.A., Nilsson, H., and Buchert, S.: Scale sizes of intense auroral electric fields observed by Cluster, Ann. Geophys., 25, 24132425, doi:10.5194/angeo-25-2413-2007, 2007.

Karlsson, T. and Marklund, G. T.: A statistical study of intense lowaltitude electric fields observed by Freja, Geophys. Res. Lett., 23, 1005, doi:10.1029/96GL00773, 1996.

Kaufmann, R. L., Ludlow, G. R., Collin, H. L., Peterson, W. K., and Burch, J. L.: Interaction of upgoing auroral $\mathrm{H}^{+}$and $\mathrm{O}^{+}$beams, J. Geophys. Res., 91, 10080, doi:10.1029/JA091iA09p10080, 1986.

Keiling, A., Rème, H., Dandouras, I., Bosqued, J. M., Parks, G. K., McCarthy, M., Kistler, L., Amata, E., Klecker, B., Korth, A., and Lundin, R.: Transient ion beamlet injections into spatially separated PSBL flux tubes observed by Cluster-CIS, Geophys. Res. Lett., 31, L12804, doi:10.1029/2004GL020192, 2004.

Kohl, J. L., Noci, G., Antonucci, E., Tondello, G., Huber, M. C. E., Cranmer, S. R., Strachan, L., Panasyuk, A. V., Gardner, L. D., Romoli, M., Fineschi, S., Dobrzycka, D., Raymond, J. C., Nicolosi, P., Siegmund, O. H. W., Spadaro, D., Benna, C., Ciaravella, A., Giordano, S., Habbal, S. R., Karovska, M., Li, X., Martin, R., Michels, J. G., Modigliani, A., Naletto, G., O’Neal, R. H., Pernechele, C., Poletto, G., Smith, P. L., and Suleiman, R. M.: UVCS/SOHO empirical determinations of anisotropic velocity distributions in the solar corona, Astrophys. J. Lett., 501, L127, doi:10.1086/311434, 1998.

Lund, E. J., Möbius, E., Tang, L., Kistler, L. M., Popecki, M. A., Klumpar, D. M., Peterson, W. K., Shelley, E. G., Klecker, B., Hovestadt, D., Temerin, M., Ergun, R. E., McFadden, J. P., Carlson, C. W., Mozer, F. S., Elphic, R. C., Strangeway, R. J., Cattell, C. A., and Pfaff, R. F.: FAST observations of preferentially accelerated $\mathrm{He}^{+}$in association with auroral electromagnetic ion cyclotron waves, Geophys. Res. Lett., 25, 2049, doi:10.1029/98GL00304, 1998.

Maggs, J. E. and Davis, T. N.: Measurements of the thicknesses of auroral structures, Planet. Space Sci., 16, 205, doi:10.1016/00320633(68)90069-X, 1968. 
Malkki, A., Koskinen, H., Boström, R., and Holback, B.: On theories attempting to explain observations of solitary waves and weak double layers in the auroral magnetosphere, Phys. Scr., 39, 787, doi:10.1088/0031-8949/39/6/023, 1989.

Marklund, G. T., Sadeghi, S., Karlsson, T., Lindqvist, P.-A., Nilsson, H., Forsyth, C., Fazakerley, A., Lucek, E. A., and Pickett, J.: Altitude distribution of the auroral acceleration potential determined from Cluster satellite data at different heights, Phys. Rev. Lett., 106, 055002, doi:10.1103/PhysRevLett.106.055002, 2011.

Marsch, E.: Kinetic physics of the solar corona and solar wind, Living Rev. Sol. Phys., 3, 1, doi:10.12942/lrsp-2006-1, 2006.

Marsch, E., Ao, X.-Z., and Tu, C.-Y.: On the temperature anisotropy of the core part of the proton velocity distribution function in the solar wind, J. Geophys. Res., 109, A04102, doi:10.1029/2003JA010330, 2004.

McFadden, J. P., Carlson, C. W., Ergun, R. E., Mozer, F. S., Temerin, M., Peria, W., Klumpar, D. M., Shelley, E. G., Peterson, W. K., Möbius, E., Kistler, L., Elphic, R., Strangeway, R., Cattell, C., and Pfaff, R.: Spatial structure and gradients of ion beams observed by FAST, Geophys. Res. Lett., 25, 2021, doi:10.1029/98GL00648, 1998.

Mende, S. B., Heetderks, H., Frey, H. U., Stock, J. M., Lampton, M., Geller, S. P., Abiad, R., Siegmund, O. H. W., Habraken, S., Renotte, E., Jamar, C., Rochus, P., Gerard, J.-C., Sigler, R., and Lauche, H.: Far ultraviolet imaging from the IMAGE spacecraft. 3. Spectral imaging of Lyman- $\alpha$ and OI $135.6 \mathrm{~nm}$, Space Sci. Rev., 91, 287, doi:10.1023/A:1005292301251, 2000.

Möbius, E., Tang, L., Kistler, L. M., Popecki, M., Lund, E. J., Klumpar, D., Peterson, W., Shelley, E. G., Klecker, B., Hovestadt, D., Carlson, C. W., Ergun, R., McFadden, J. P., Mozer, F., Temerin, M., Cattell, C., Elphic, R., Strangeway, R., and Pfaff, R.: Species dependent energies in upward directed ion beams over auroral arcs as observed with FAST TEAMS, Geophys. Res. Lett., 25, 2029, doi:10.1029/98GL00381, 1998.

Parks, G. K., Lee, E., Fu, S. Y., Fillingim, M., Dandouras, I., Cui, Y. B., Hong, J., and Rème, H.: Outflow of low-energy $\mathrm{O}^{+}$ion beams observed during periods without substorms, Ann. Geophys., 33, 333-344, doi:10.5194/angeo-33-333-2015, 2015.
Partamies, N., Donovan, E., and Knudsen, D.: Statistical study of inverted-V structures in FAST data, Ann. Geophys., 26, 14391449, doi:10.5194/angeo-26-1439-2008, 2008.

Reiff, P. H., Collin, H. L., Craven, J. D., Burch, J. L., Winningham, J. D., Shelley, E. G., Frank, L. A., and Friedman, M. A.: Determination of auroral electrostatic potentials using high- and low-altitude particle distributions, J. Geophys. Res., 93, 7441, doi:10.1029/JA093iA07p07441, 1988.

Rème, H., Aoustin, C., Bosqued, J. M., Dandouras, I., Lavraud, B., Sauvaud, J. A., Barthe, A., Bouyssou, J., Camus, Th., Coeur-Joly, O., Cros, A., Cuvilo, J., Ducay, F., Garbarowitz, Y., Medale, J. L., Penou, E., Perrier, H., Romefort, D., Rouzaud, J., Vallat, C., Alcaydé, D., Jacquey, C., Mazelle, C., d'Uston, C., Möbius, E., Kistler, L. M., Crocker, K., Granoff, M., Mouikis, C., Popecki, M., Vosbury, M., Klecker, B., Hovestadt, D., Kucharek, H., Kuenneth, E., Paschmann, G., Scholer, M., Sckopke, N., Seidenschwang, E., Carlson, C. W., Curtis, D. W., Ingraham, C., Lin, R. P., McFadden, J. P., Parks, G. K., Phan, T., Formisano, V., Amata, E., Bavassano-Cattaneo, M. B., Baldetti, P., Bruno, R., Chionchio, G., Di Lellis, A., Marcucci, M. F., Pallocchia, G., Korth, A., Daly, P. W., Graeve, B., Rosenbauer, H., Vasyliunas, V., McCarthy, M., Wilber, M., Eliasson, L., Lundin, R., Olsen, S., Shelley, E. G., Fuselier, S., Ghielmetti, A. G., Lennartsson, W., Escoubet, C. P., Balsiger, H., Friedel, R., Cao, J.-B., Kovrazhkin, R. A., Papamastorakis, I., Pellat, R., Scudder, J., and Sonnerup, B.: First multispacecraft ion measurements in and near the Earth's magnetosphere with the identical Cluster ion spectrometry (CIS) experiment, Ann. Geophys., 19, 1303-1354, doi:10.5194/angeo19-1303-2001, 2001.

Shelley, E. G., Johnson, R. G., and Sharp, R. D.: Satellite observations of energetic heavy ions during a geomagnetic storm, J. Geophys. Res., 77, 6104, doi:10.1029/JA077i031p06104, 1972.

Temerin, M., Cerny, K., Lotko, W., and Mozer, F. S.: Observations of double layers and solitary waves in the auroral plasma, Phys. Rev. Lett., 48, 1175, doi:10.1103/PhysRevLett.48.1175, 1982.

Tsyganenko, N. A. and Stern, D. P.: Modeling the global magnetic field of the large-scale Birkeland current systems, J. Geophys. Res., 101, 27187, doi:10.1029/96JA02735, 1996. 